\title{
Increased expression of calpain and elevated activity of calcineurin in the myocardium of patients with congestive heart failure
}

\author{
DACHUN YANG* ${ }^{*}$ SHUANGTAO MA*, YAN TAN, DE LI, BING TANG, \\ XIN ZHANG, MEIQIN SUN and YONGJIAN YANG \\ Department of Cardiology, General Hospital of PLA Chengdu Military Area Command, Chengdu 610083, P.R. China
}

Received February 25, 2010; Accepted April 23, 2010

DOI: 10.3892/ijmm_00000448

\begin{abstract}
The angiotensin (Ang) II/Ang II receptor (ATR)associated calcium signaling pathway is the major cause of ventricular remodelling in patients with congestive heart failure (CHF). However, the calcium-regulated proteinases responsible for Ang II-induced remodelling are not well understood. We investigated the profiles of the Ang II/ ATR/calpain/calcineurin (CaN) pathway in human failing heart. We measured both the plasma and cardiac levels of Ang II and cardiac mRNA expression of ATR in 39 patients with $\mathrm{CHF}$ and 38 healthy controls. Importantly, protein expression of calpains, cleavage of cain/cabin1 and activity of CaN were tested. Both plasma and cardiac levels of Ang II were significantly increased in patients with CHF (both $\mathrm{p}<0.01$ ), and the plasma Ang II concentration was closely correlated with the parameters of ventricular remodelling $(\mathrm{r}= \pm 0.29-0.65, \mathrm{p}<0.05$ or $<0.01)$. In addition, the cardiac level of AT1R but not AT2R was significantly upregulated in mild failing hearts $(p<0.05)$ but dramatically downregulated in severe failing ones $(\mathrm{p}<0.01)$. CHF was associated with a marked upregulation of calpains, an increased cleavage of cain/cabin1, and the activation of $\mathrm{CaN}$ in the failing ventricular tissue. In patients with $\mathrm{CHF}$, calpain upregulation was associated with an increase in cleavage of cain/cabin1 and the activation of $\mathrm{CaN}$, indicating that these changes in calciumregulated proteinases contribute to Ang II-induced cardiac remodelling.
\end{abstract}

\section{Introduction}

Congestive heart failure (CHF) is a growing public health problem (1). Cardiac remodelling plays a central role in the

Correspondence to: Dr Yongjian Yang, Department of Cardiology, General Hospital of PLA Chengdu Military Area Command, Tianhui, Jinniu District, Chengdu 610083, Sichuan Province, P.R. China

E-mail: yongjiany@yahoo.cn

${ }^{*}$ Contributed equally

Key words: calpain, calcineurin, congestive heart failure progression of heart failure and is also associated with less favorable survival (2). One potential central molecule involved in ventricular remodelling is angiotensin (Ang) II (3), whose effects are mediated by alterations in calcium handling and consequent activation of several types of proteases, including matrix metalloproteinases (MMPs) and calpains (4). We profiled the expression of MMPs in both human (unpublished data) and animal failing heart (5). Calpains are another class of proteases (a family of calcium-activated cysteine proteases) not yet directly associated with ventricular remodelling $(6,7)$. Two major isoforms, $\mu$ - and m-calpain, are ubiquitously expressed and require micromolar and millimolar concentrations of calcium, respectively (8). Additionally, calpain activity is tightly controlled by its endogenous inhibitor calpastatin. The calpain/calpastatin system in heart failure, and particularly its potential role in the regulation of ventricular remodelling, is only poorly understood.

Calpains have been proposed to cleave several types of cytoskeletal proteins, membrane proteins and enzymes (9). Cain/cabin1 has been recognized as a new calpain substrate (10). Furthermore, cain/cabin1 has also been identified as a protein that binds to and inhibits calcineurin $(\mathrm{CaN})$ with its C-terminal region (11-13). Lim and Molkentin reported that $\mathrm{CaN}$, a calcium-regulated phosphatase, may play a critical role in the progressive nature of human heart failure (14). Therefore, the activity of calcineurin can be regulated through the upregulation of calpains and a consequent increase in cain/cabin1 cleavage.

In the present study, we sought to determine whether calpain upregulation, an increase in cain/cabin1 cleavage and elevation in $\mathrm{CaN}$ exist in patients with $\mathrm{CHF}$.

\section{Materials and methods}

Study subjects. We performed this study on patients with $\mathrm{CHF}$ due to valvular heart disease and healthy controls. An echocardiogram was performed to get the ventricular characteristics of the CHF patients, who were classified into functional groups according to the New York Heart Association (NYHA) classification. Failing heart samples were obtained from patients undergoing mitral valve replacement surgery with NYHA class II ( $n=6$ males, $n=6$ females; mean age $45 \pm 6$ years), class III ( $n=8$ males, $n=7$ females; mean age $42 \pm 7$ years) or class IV ( $n=6$ males, $n=6$ females; mean age 
$48 \pm 8$ years) heart failure, while nonfailing heart samples (used as controls, $n=5$ males, $n=3$ females; mean age $40 \pm 3$ years) were obtained from healthy heart donors whose hearts were explanted to obtain pulmonary and aortic valves for transplant surgery. Additionally, plasma samples were collected from the aforementioned 38 heart failure patients and another 30 healthy volunteers $(n=15$ males, $n=15$ females; mean age $43 \pm 4$ years). Tissue samples were quickly frozen in liquid nitrogen and stored at $-80^{\circ} \mathrm{C}$. After blood samples were centrifuged at $3000 \mathrm{rpm}$ for $10 \mathrm{~min}$ at $4^{\circ} \mathrm{C}$, the plasma was frozen and stored at $-80^{\circ} \mathrm{C}$ until analyzed.

All studies conformed to the Declaration of Helsinki, and all protocols were approved by the Hospital Ethics Committee. Informed consent for the use of tissue samples was obtained from patients undergoing cardiac surgery.

Radioimmunoassay. The plasma concentration of Ang II was quantified using an Ang II RIA kit (North Institute Bio Tech, Beijing, China) as reported previously (15). Ang II antiserum was incubated with Ang II in samples for $6 \mathrm{~h}$ at $4^{\circ} \mathrm{C}$. Competitive binding of tracer, ${ }^{125} \mathrm{I}$-Ang II, was achieved during a subsequent incubation for $18 \mathrm{~h}$ at $4^{\circ} \mathrm{C}$. Goat anti-rabbit $\gamma$ globulin bound on solid phase was used for separation of bound and free radiolabeled tracer. The supernatant was aspirated from the residue after centrifugation at $3000 \mathrm{rpm}$ for $15 \mathrm{~min}$. The residue was then counted for $1 \mathrm{~min}$ in an automatic gamma counter (1470 Wizard, PerkinElmer Life Sciences, Boston, MA, USA). The concentrations of Ang II in the samples were determined from standard curve plots of bound relative to maximum binding percentages versus Ang II levels.

Ventricular samples were boiled in $0.1 \mathrm{~mol} / \mathrm{l}$ acetic acid for $10 \mathrm{~min}$ and then homogenized. Samples were cooled on ice followed by centrifugation at $3000 \mathrm{rpm}$ for $20 \mathrm{~min}$ at $4^{\circ} \mathrm{C}$. The supernatant was used to determine the Ang II levels using radioimmunoassay as described in the previous section.

Reverse transcriptase-polymerase chain reaction ( $R T-P C R)$. Total RNA was extracted from ventricular tissue with the Trizol reagent (Gibco-BRL) according to the manufacturer's instructions. Semiquantitative RT-PCR for Ang II receptor type 1 (AT1R) and AT2R was performed as described previously. The primers for human AT1R mRNA were as follows: 5'-CCA GCG TCA GTT TCA ACC-3' (sense) and 5'-TAG GGC CTT CCA AAT AAG AGT A-3' (antisense), the expected PCR product is $350 \mathrm{bp}$. The primers for human AT2R mRNA were as follows: 5'-TGT CAT CTA CCC CTT TCT GTC TC-3' (sense) and 5'-GTC ACG CTA CCC CTT TCT GTC TC-3' (antisense), the expected PCR product is $322 \mathrm{bp}$. The primers for human GAPDH mRNA were as follows: 5'-ACG GCA AAT TCA ACG GCA CAG TCA-3' (sense) and 5'-TGG GGG CAT CGG CAG AAG G-3' (antisense), the expected PCR product is $231 \mathrm{bp}$.

Western blot analysis. Western blot assay was performed as reported previously (5). Ventricular samples from nonfailing and failing hearts were homogenized in lysis buffer containing $1 \%$ Triton X-100, $150 \mathrm{mM} \mathrm{NaCl}, 1 \mathrm{mM}$ EDTA, $2.5 \mathrm{mM}$ sodium pyrophosphate, $1 \mathrm{mM}$ B-glycerophosphate, $1 \mathrm{mM}$ $\mathrm{Na}_{3} \mathrm{VO}_{4}, 1 \mu \mathrm{g} / \mathrm{ml}$ leupeptin, $1 \mu \mathrm{g} / \mathrm{ml}$ aprotinin and $20 \mathrm{mM}$
Table I. Ang II levels of the examined subjects.

\begin{tabular}{lll}
\hline Group & Plasma levels $(\mathrm{pg} / \mathrm{ml})$ & Cardiac levels $(\mathrm{pg} / \mathrm{ml})$ \\
\hline Control subjects & $278.21 \pm 64.76(\mathrm{n}=30)$ & $245.30 \pm 26.10(\mathrm{n}=8)$ \\
NYHA class II & $482.92 \pm 122.43^{\mathrm{a}}(\mathrm{n}=12)$ & $368.10 \pm 84.10^{\mathrm{a}}(\mathrm{n}=12)$ \\
NYHA class III & $507.85 \pm 70.03^{\mathrm{a}}(\mathrm{n}=15)$ & $381.20 \pm 47.0^{\mathrm{a}}(\mathrm{n}=15)$ \\
NYHA class IV & $589.25 \pm 28.70^{\mathrm{a}}(\mathrm{n}=12)$ & $391.60 \pm 20.64^{\mathrm{a}}(\mathrm{n}=12)$ \\
\hline
\end{tabular}

Data are presented as means \pm SD. Ang II, angiotensin II; NYHA, New York Heart Association. ${ }^{a} \mathrm{p}<0.01$ when compared with control subjects.

Tris ( $\mathrm{pH}$ 7.5). The protein concentration was determined with Bio-Rad protein assay reagent (Bio-Rad Laboratories, USA). Equal amounts $(50 \mu \mathrm{g})$ of protein from heart extracts were separated by $12 \%$ SDS-PAGE gels. The samples were then electroblotted onto a nitrocellulose membrane (Boehringer Mannheim Corp., USA) and probed with antibodies against $\mu$-calpain, m-calpain, cain/cabin1, $\Delta$ cain/cabin1, CaN and phospho-CaN (1:500 dilution, polyclonal, supplied by Dr D. $\mathrm{Mu}$, University of California-Francisco, San Francisco, CA, USA). After washing, the membrane was incubated with a horseradish peroxidase-conjugated secondary antibody (1:1000 dilution, Santa Cruz Biotechnology, USA), and the bound antibody was visualized using a colored reaction. The relative band densities were quantified by densitometry using the Multi-Analyst software package (Bio-Rad). Equal loading of protein was confirmed by measuring $\beta$-actin expression.

Statistical analysis. All data are presented as mean \pm standard deviation (SD). Comparisons between groups were determined by one-way ANOVA with the Student's t-test post hoc test (SPSS Inc., Chicago, IL, USA). A two-sided p-value of $<0.05$ was considered statistically significant.

\section{Results}

Clinical characteristics and Ang II/ATR profiles of subjects. The patients exhibited a significant increase in cardiothoracic ratio (CTR), left ventricular end diastolic diameter (LVED), left ventricular posterior wall thickness (LVPW) and interventricular septum thickness (IVS), but a marked decrease in left ventricular ejection fraction (LVEF), fraction shortening (FS), cardiac output (CO) or cardiac index (CI) compared to control subjects (data not shown). Both plasma and cardiac levels of Ang II were significantly increased in patients with mild CHF (NYHA classes II, $\mathrm{p}<0.01$ ) as compared to levels in the control subjects and were further increased in patients with severe CHF (NYHA classes III and IV; both $\mathrm{p}<0.01$ ) (Table I). Univariate correlation analysis showed that the plasma Ang II concentration was positively correlated with CTR, LVED, LVPW and IVS (Table II). Conversely, the plasma Ang II concentration was negatively correlated with LVEF, FS, CO and CI (Table II). The AT1R mRNA level was slightly but significantly higher in mild failing (NYHA classes II, $\mathrm{p}<0.05$ ) than in nonfailing hearts; however, it was notably reduced in severe failing hearts (NYHA classes III and IV, both $\mathrm{p}<0.01$ ) when compared with that in nonfailing 


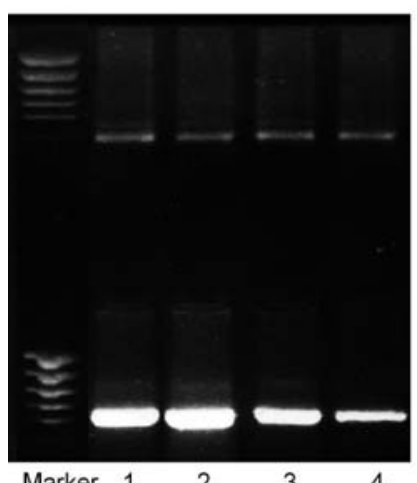

Marker 1

C

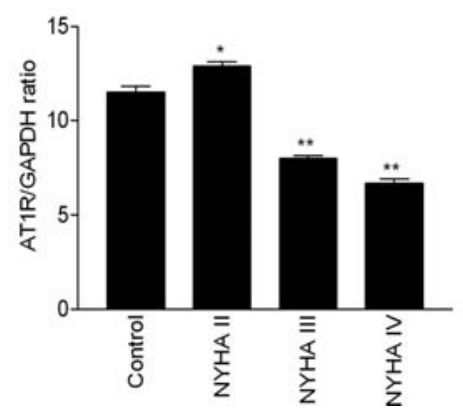

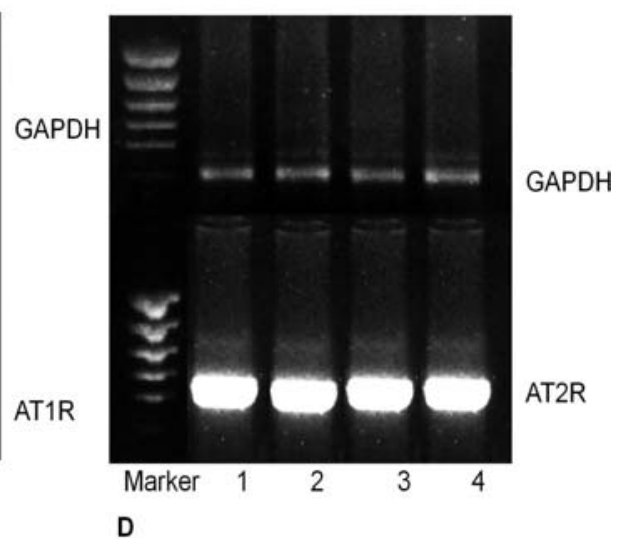

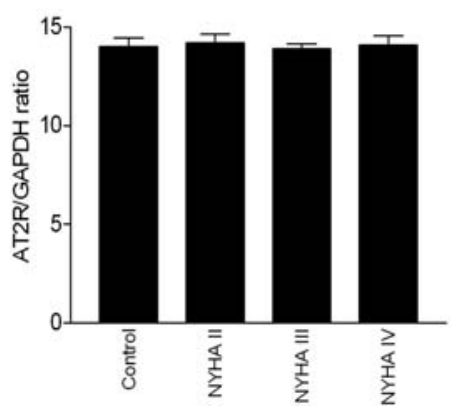

Figure 1. Representative RT-PCR for AT1R (A) and AT2R (B) mRNA expression in the ventricular tissues from control subjects and patients with CHF. Lane 1, control subjects; 2, NYHA class II; 3, NYHA class III; 4, NYHA class IV. Bar graphs depict mRNA levels of AT1R (C) and AT2R (D) normalized to the level of GAPDH ( $n=8$ for each group). ${ }^{*} \mathrm{p}<0.05,{ }^{* *} \mathrm{p}<0.01$ compared with the nonfailing control hearts.

Table II. Correlations between plasma Ang II levels and clinical parameters.

\begin{tabular}{lcc}
\hline & r & P-value \\
\hline CTR & 0.65 & $<0.01$ \\
LVED (mm) & 0.39 & $<0.01$ \\
LVPW (mm) & 0.31 & $<0.05$ \\
IVS (mm) & 0.29 & $<0.05$ \\
LVEF (\%) & -0.53 & $<0.01$ \\
FS (\%) & -0.45 & $<0.01$ \\
CO (liter/min) & -0.39 & $<0.01$ \\
CI (liter/min $\left./ \mathrm{m}^{2}\right)$ & -0.35 & $<0.05$ \\
\hline
\end{tabular}

Ang II, angiotensin II; CTR, cardiothoracic ratio; LVED, left ventricular end diastolic diameter; LVPW, left ventricular posterior wall thickness; IVS, interventricular septum thickness; LVEF, left ventricular ejection fraction; FS, fraction shortening; CO, cardiac output; CI, cardiac index Values are presented as correlation coefficients, where appropriate with p-values.

ones (Fig. 1A and C). Conversely, AT2R mRNA expression did not significantly differ in failing and nonfailing hearts (Fig. 1B and D).

Calpain expression in failing hearts. The protein level of $\mu$-calpain, but not m-calpain, was higher in NYHA class II failing hearts compared to that in nonfailing ones. In
A

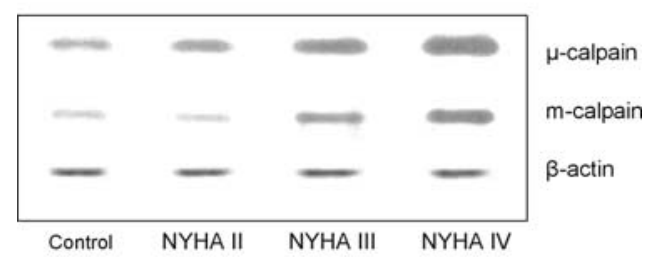

B

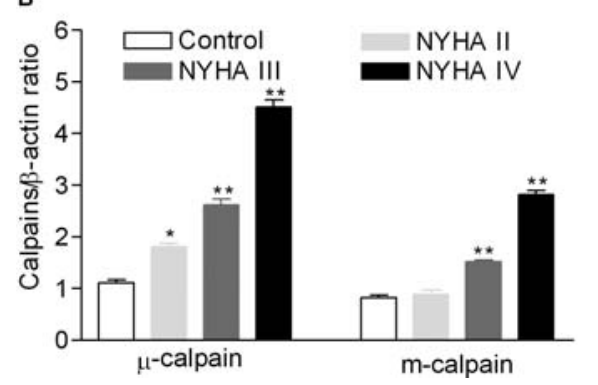

Figure 2. (A) Representative Western blots for $\mu$ - and m-calpain protein expression in the ventricular tissues from control subjects and patients with NYHA class II/III/IV heart failure. (B) Bar graphs depict protein levels of $\mu$ and $\mathrm{m}$-calpain normalized to the level of $\mathrm{B}$-actin ( $\mathrm{n}=8$ for each group). ${ }^{*} \mathrm{p}<0.05,{ }^{* *} \mathrm{p}<0.01$ compared with nonfailing control hearts.

addition, both $\mu$-calpain and m-calpain protein levels were significantly increased in severe failing hearts (NYHA classes III and IV, both $\mathrm{p}<0.01$ ) when compared with levels in the control group (Fig. 2). 


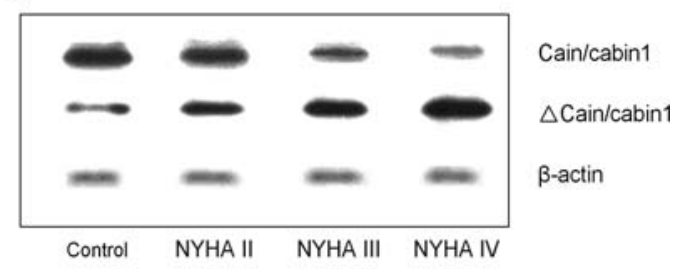

B

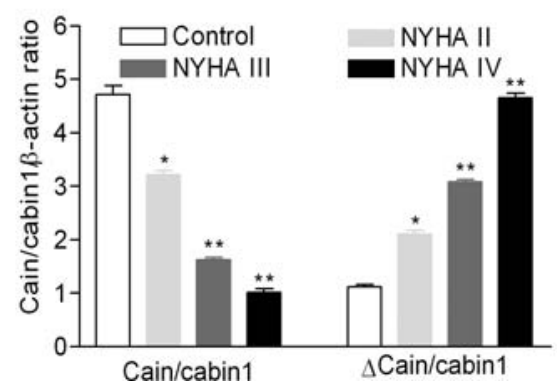

Figure 3. (A) Representative Western blots for cain/cabin1 and its cleavage product $(\Delta$ cain/cabin 1$)$ expression in the ventricular tissues from control subjects and patients with NYHA class II/III/IV heart failure. (B) Bar graphs depict protein levels of cain/cabin1 and $\Delta$ cain/cabin1 normalized to the level of $B$-actin ( $\mathrm{n}=8$ for each group). ${ }^{*} \mathrm{p}<0.05,{ }^{* *} \mathrm{p}<0.01$ compared with nonfailing control hearts.

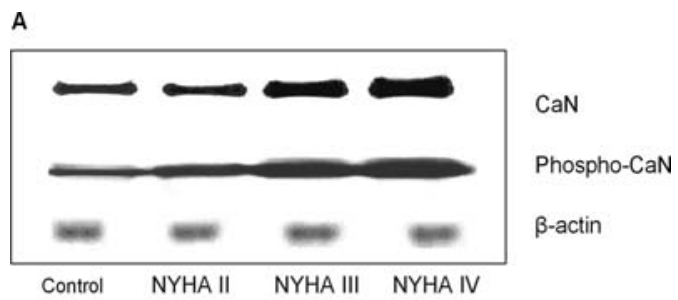

B

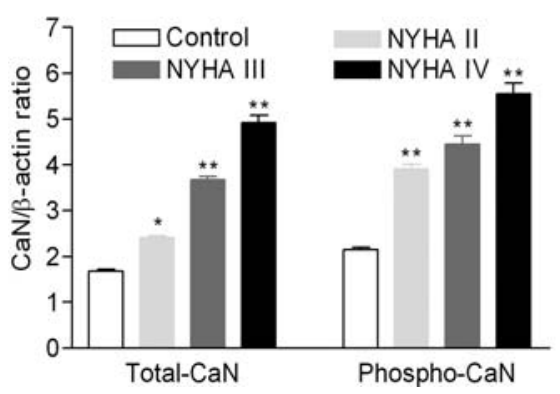

Figure 4. (A) Representative Western blots for total and phosphorylated $\mathrm{CaN}$ protein expression in the ventricular tissues from control subjects and patients with NYHA class II/III/IV heart failure. (B) Bar graphs depict protein levels of total and phosphorylated $\mathrm{CaN}$ normalized to the level of $\beta$-actin $(\mathrm{n}=8$ for each group). ${ }^{*} \mathrm{p}<0.05,{ }^{* *} \mathrm{p}<0.01$ compared with nonfailing control hearts.

Cain/cabinl cleavage in failing hearts. We next examined the cleavage of cain/cabin1, a novel calpain substrate, in the failing hearts. Western blot analysis showed that the cain/ cabin1 protein level was substantially reduced in mild failing hearts (NYHA classes II, p<0.05) and was further decreased in severe failing ones (NYHA classes III and IV; both $\mathrm{p}<0.01$ )

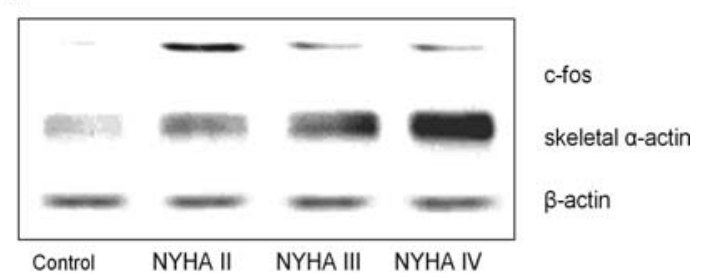

B

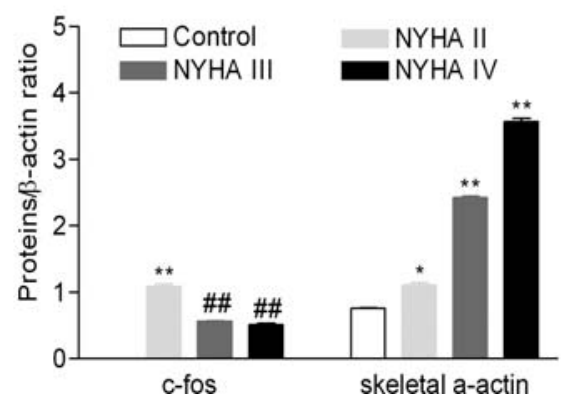

Figure 5. (A) Representative Western blots for c-fos and skeletal $\alpha$-actin expression in the ventricular tissues from control subjects and patients with NYHA class II/III/IV heart failure. (B) Bar graphs depict protein levels of c-fos and skeletal $\alpha$-actin expression normalized to the level of $\beta$-actin $(n=8$ for each group). ${ }^{*} \mathrm{p}<0.05,{ }^{* *} \mathrm{p}<0.01$ compared with nonfailing control hearts, ${ }^{\#} \mathrm{p}<0.01$ compared with NYHA class II failing hearts.

(Fig. 3). Consequently, the generation of $\Delta$ cain/cabin 1 , indicating a cleavage product of cain/cabin1, was significantly increased in failing hearts compared to that in the control group ( $\mathrm{p}<0.05$ or $<0.01)$ (Fig. 3).

CaN activity in failing hearts. As the level of cain/cabin1, a potential $\mathrm{CaN}$ inhibitor, was markedly downregulated in failing hearts, we then determined the total and phosphorylated CaN levels in ventricular tissue. Notably, both total and phosphorylated $\mathrm{CaN}$ protein levels were actually increased in failing hearts when compared to these levels in nonfailing hearts $(\mathrm{p}<0.05$ or $<0.01)$ (Fig. 4).

Specific protein expression in failing hearts. Considering CaN might play an important role in pressure overload-induced reprogramming of some specific genes, such as the immediate early response genes and fetal genes in the heart, we identified the protein expression of $\mathrm{c}$-fos and skeletal $\alpha$-actin in ventricular tissues. There was a slight amount of c-fos protein expressed in nonfailing hearts. The c-fos was markedly upregulated in mild failing hearts (NYHA classes II, $\mathrm{p}<0.01$ ); however, it was significantly downregulated in severe failing compared with that in mild failing ones (NYHA classes III and IV; both $\mathrm{p}<0.01$ ) (Fig. 5). Additionally, in patients with heart failure, a stepwise increase in skeletal $\alpha$-actin level was found depending on the heart failure severity graded using NYHA classification ( $<<0.05$ or $<0.01)$ (Fig. 5).

\section{Discussion}

The novel finding of the present study is that the circulating level of Ang II was closely related to clinical parameters 
representing heart failure severity and cardiac remodelling, including CTR, LVED, LVPW, IVS, LVEF, FS, CO and CI in patients with CHF. Additionally, the cardiac level of AT1R but not AT2R was altered with the natural course of CHF in patients, indicating that the action of Ang II was likely mediated by AT1R rather than AT2R. CHF was associated with an upregulation of calpains and a consequent increase in cain/cabin 1 cleavage, resulting in activation of $\mathrm{CaN}$ in the failing ventricular tissue.

Ventricular remodelling is a well characterized cellular event in failing heart with valvular heart disease and plays a crucial role in the development of $\mathrm{CHF}$. Moreover, cardiac remodelling occurs in response to activation of the reninangiotensin-aldosterone system. It has been reported that the plasma Ang II concentration is higher in patients with $\mathrm{CHF}$ compared to healthy subjects (16). The present study demonstrated that the plasma Ang II level increased gradually dependent on the severity of heart failure. Moreover, we also found that the cardiac level of Ang II was dramatically parallel to its circulating concentration. These findings suggest that both the circulating and cardiac local level of Ang II contribute to the ventricular remodelling in the failing heart. This study also showed that the effects of Ang II are mediated by AT1R rather than AT2R. However, the underlying mechanisms responsible for the upregulation of AT1R in mild heart failure and downregulation in severe heart failure remain elusive.

Ang II-induced cardiovascular remodelling was partly attributed to the activation of many types of proteases (4). Recently, we reported that AT1R blockade markedly suppressed the expression of MMPs in the failing heart after myocardial infarction (5). A previous study demonstrated that calpains were involved in the development of Ang IIinduced vascular remodelling (4). Additionally, the activation of calpains has been identified in several types of cardiovascular diseases, including aortic aneurysm and diabetic cardiomyopathy $(17,18)$. Furthermore, inhibition of calpains by treatment with a pharmacological inhibitor or overexpression of calpastatin may protect the heart from ischemiareperfusion injury (19-21). The present study further demonstrated that expression of $\mu$ - and m-calpain significantly increased with the progression of heart failure, indicating that calpains are implicated in the ventricular remodelling in valvular heart disease caused by $\mathrm{CHF}$. These findings further our understanding of the role of calpains in non-ischemic heart failure and propose a novel target against ventricular remodelling.

Calpain has been proposed to participate in the pathogenesis of several diseases by cleaving structural proteins and enzymes (9). Previously, cain/cabin1 was identified as a novel calpain substrate (10). The present study revealed that calpain upregulation is associated with the increased cleavage of cain/cabin1 in the failing heart. This result suggests that loss of cain/cabin 1 would exert the downstream processes.

$\mathrm{CaN}$, a calcium-regulated phosphatase, is activated in heart failure (22-24). Moreover, cain/cabin1 may bind to $\mathrm{CaN}$ and inhibit its activity (11-13). As expected, the present study demonstrated that both the total and phosphorylated $\mathrm{CaN}$ were significantly upregulated in failing hearts with an increase in cain/cabin1 cleavage. Accordingly, CaN activation in the failing heart may be due to the upregulation of calpains.
It has been reported that $\mathrm{CaN}$ might play an important role in pressure overload-induced reprogramming of some specific genes, including c-fos and skeletal $\alpha$-actin contributing to the development of ventricular remodelling (25). In the present study, we showed that both the c-fos and skeletal $\alpha$-actin actually change with the natural course of heart failure, which may be associated with the activation of CaN.

There are limitations to this study that must be recognized. The present study showed a parallel change in Ang II/AT1R, calpain, cain/cabin 1 and $\mathrm{CaN}$ in patients with $\mathrm{CHF}$, but did not provide direct evidence indicating the association among these molecules. This issue requires further investigation using animal or cellular experiments. Additionally, only the protein expression levels of calpains were evaluated in this study. The activity of these enzymes should be investigated in further studies.

In conclusion, we propose that Ang II/AT1R/calpain/ cain/cabin $1 / \mathrm{CaN}$ may be a potential pathway mediating ventricular remodelling. These results further our understanding of the role of the calpain system in human myocardial remodelling and provide a novel conceptual framework for future research regarding therapeutic interventions against myocardial remodelling aimed at calpains and $\mathrm{CaN}$.

\section{Acknowledgements}

The authors would like to thank Dr Dezhi Mu of the University of California-San Francisco for providing the primary antibodies. This study was supported by the grants from the Medical Scientific Research Program of PLA during the 11th Five-Year Plan Period (to Yang YJ, No. 06MB188) and the Medical Scientific Research Program of PLA Chengdu Military Area Command during the 11th Five-Year Plan Period (to Yang DC, No. MB09023).

\section{References}

1. Demirovic J, Prineas R and Rudolph M: Epidemiology of congestive heart failure in three ethnic groups. Congest Heart Fail 7: 93-96, 2001.

2. Takano H, Hasegawa H, Nagai T and Komuro I: Implication of cardiac remodeling in heart failure: mechanisms and therapeutic strategies. Intern Med 42: 465-469, 2003.

3. Mehta PK and Griendling KK: Angiotensin II cell signaling: physiological and pathological effects in the cardiovascular system. Am J Physiol Cell Physiol 292: C82-C97, 2007.

4. Letavernier E, Perez J, Bellocq A, Mesnard L, de Castro Keller A, Haymann JP and Baud L: Targeting the calpain/calpastatin system as a new strategy to prevent cardiovascular remodeling in angiotensin II-induced hypertension. Circ Res 102: 720-728, 2008 .

5. Yang D, Ma S, Li D, Tang B and Yang Y: Angiotensin II receptor blockade improves matrix metalloproteinases/tissue inhibitor of matrix metalloproteinase- 1 balance and restores fibronectin expression in rat infarcted myocardium. Biochem Biophys Res Commun 388: 606-611, 2009.

6. Croall DE and DeMartino GN: Calcium-activated neutral protease (calpain) system: structure, function, and regulation. Physiol Rev 71: 813-847, 1991.

7. Goll DE, Thompson VF, Li H, Wei W and Cong J: The calpain system. Physiol Rev 83: 731-801, 2003.

8. Heidrich FM and Ehrlich BE: Calcium, calpains, and cardiac hypertrophy: a new link. Circ Res 104: e19-e20, 2009.

9. Saido TC, Sorimachi H and Suzuki K: Calpain: new perspectives in molecular diversity and physiological-pathological involvement. FASEB J 8: 814-822, 1994. 
10. Kim MJ, Jo DG, Hong GS, Kim BJ, Lai M, Cho DH, Kim KW, Bandyopadhyay A, Hong YM, Kim DH, Cho C, Liu JO, Snyder SH and Jung YK: Calpain-dependent cleavage of cain/cabin1 activates calcineurin to mediate calcium-triggered cell death. Proc Natl Acad Sci USA 99: 9870-9875, 2002.

11. Lai MM, Burnett PE, Wolosker H, Blackshaw S and Snyder SH: Cain, a novel physiologic protein inhibitor of calcineurin. J Biol Chem 273: 18325-18331, 1998.

12. Sun L, Youn HD, Loh C, Stolow M, He W and Liu JO: Cabin 1, a negative regulator for calcineurin signaling in $\mathrm{T}$ lymphocytes. Immunity 8: 703-711, 1998

13. Lai MM, Luo HR, Burnett PE, Hong JJ and Snyder SH: The calcineurin-binding protein cain is a negative regulator of synaptic vesicle endocytosis. J Biol Chem 275: 34017-34020, 2000.

14. Lim HW and Molkentin JD: Calcineurin and human heart failure. Nat Med 5: 246-247, 1999.

15. Naik GO, Moe GW and Armstrong PW: Specific and nonspecific measurements of tissue angiotensin II cascade members. J Pharm Biomed Anal 24: 947-955, 2001.

16. Van de Wal RM, Plokker HW, Lok DJ, Boomsma F, van der Horst FA, van Veldhuisen DJ, van Gilst WH and Voors AA: Determinants of increased angiotensin II levels in severe chronic heart failure patients despite ACE inhibition. Int J Cardiol 106: 367-372, 2006.

17. Pilop C, Aregger F, Gorman RC, Brunisholz R, Gerrits B Schaffner T, Gorman JH III, Matyas G, Carrel T and Frey BM Proteomic analysis in aortic media of patients with Marfan syndrome reveals increased activity of calpain 2 in aortic aneurysms. Circulation 120: 983-991, 2009.

18. Li Y, Feng Q, Arnold M and Peng T: Calpain activation contributes to hyperglycaemia-induced apoptosis in cardiomyocytes. Cardiovasc Res 84: 100-110, 2009.
19. Yoshikawa Y, Hagihara H, Ohga Y, Nakajima-Takenaka C, Murata KY, Taniguchi S and Takaki M: Calpain inhibitor-1 protects the rat heart from ischemia-reperfusion injury: analysis by mechanical work and energetics. Am J Physiol Heart Circ Physiol 288: H1690-H1698, 2005.

20. Khalil PN, Neuhof C, Huss R, Pollhammer M, Khalil MN Neuhof H, Fritz H and Siebeck M: Calpain inhibition reduces infarct size and improves global hemodynamics and left ventricular contractility in a porcine myocardial ischemia/ reperfusion model. Eur J Pharmacol 528: 124-131, 2005.

21. Maekawa A, Lee JK, Nagaya T, Kamiya K, Yasui K, Horiba M, Miwa K, Uzzaman M, Maki M, Ueda Y and Kodama I: Overexpression of calpastatin by gene transfer prevents troponin I degradation and ameliorates contractile dysfunction in rat hearts subjected to ischemia/reperfusion. J Mol Cell Cardiol 35: 1277-1284, 2003.

22. Williams RS: Calcineurin signaling in human cardiac hypertrophy. Circulation 105: 2242-2243, 2002.

23. Ritter O, Hack S, Schuh K, Rothlein N, Perrot A, Osterziel KJ, Schulte HD and Neyses L: Calcineurin in human heart hypertrophy. Circulation 105: 2265-2269, 2002.

24. Wilkins BJ and Molkentin JD: Calcineurin and cardiac hypertrophy: where have we been? Where are we going? J Physiol 541: 1-8, 2002

25. Zou Y, Hiroi Y, Uozumi H, Takimoto E, Toko H, Zhu W, Kudoh S, Mizukami M, Shimoyama M, Shibasaki F, Nagai R, Yazaki Y and Komuro I: Calcineurin plays a critical role in the development of pressure overload-induced cardiac hypertrophy. Circulation 104: 97-101, 2001. 